\title{
Выявление контрафактной продукции в области микроэлектроники
}

\author{
П. Гребенщиков ${ }^{1}$
}

УДК 621.382 | ВАК 05.27 .06

\begin{abstract}
Проблема контрафакта в микроэлектронной промышленности стоит очень остро, объем такой продукции растет с каждым годом. По некоторым оценкам, компании - производители электроники ежегодно теряют около 100 млрд долларов из-за подделок. Эта цифра, отражающая только прибыль, которой мошенники лишают производителей, не учитывает дополнительные расходы на ремонт и техническое обслуживание, вызванные неисправными поддельными изделиями, а также затраты на выявление таких компонентов. Для корректного обнаружения контрафакта в микроэлектронике применяют ряд физических и электрических методов. Рассмотрим виды контрафактной продукции и основные методы обнаружения подделок.
\end{abstract}

Д ля производителя электронного оборудования идентифицировать контрафактную продукцию среди тысяч компонентов, использованных для сборки системы, достаточно сложно. В некоторых случаях подделка может быть введена на предыдущих этапах в цепочке поставок и является частью модуля или сборки, продаваемой авторитетной компанией. Большая часть производителей не располагает ресурсами для отслеживания фактического происхождения каждого компонента. Иногда изделия могут работать, по крайней мере при выполнении некоторых функций, в течение короткого периода времени.

Микросхема становится привлекательной целью для производителей контрафакта только в том случае, если рыночный спрос на нее очень высокий. Например, когда производитель прекращает выпускать определенный тип микросхем, любой потенциальный потребитель вынужден покупать изделие через дистрибьютора, у которого этот продукт есть в запасе. Со временем микросхема становится дефицитной, ее стоимость увеличивается и, соответственно, возрастает вероятность подделки товара недобросовестными производителями.

\section{ВИДЫ КОНТРАФАКТНОЙ ПРОДУКЦИИ}

Можно отметить следующие основные виды контрафактных изделий:

- повторно используемые, перемаркированные;

- клонированные продукты;

- микросхемы с замененным кристаллом.

АО «ТЕСТПРИБОР», начальник ИЛ ЭКБ.
80\% контрафактных продуктов составляют повторно используемые изделия, которые уже применялись в оборудовании или устройствах. Отходы электроники собираются и продаются в развивающиеся страны или в другие учреждения. Вышедшие из строя устройства разбираются на запасные части, компоненты извлекаются из печатных плат при очень высокой температуре, а затем реализуются на рынке как новые изделия. С помощью специального оборудования демонтированным компонентам придается товарный вид - стирается старая надпись, создается матовая поверхность, наносится новая надпись, напоминающая прежнюю, чистятся и формируются “непаяные» выводы и т.д. Кроме того, компоненты перемаркируются, чтобы исправить год производства микросхемы, изменить уровень качества и т.д.

Клонированные компоненты выпускаются неавторизованными производителями, не имеющими законных прав на производство кристалла. Само по себе клонирование - процесс копирования дизайна мошенниками, преимущественно для уменьшения больших затрат на разработку компонента.

Фальсификация возможна на уровне кристалла, когда производитель контрафакта устанавливает в микросхему кристалл, который по характеристикам хуже оригинального. Также может быть установлен чип со скрытой функциональностью («аппаратный троян»), и тогда секретная информация от чипа передается потенциальному противнику. Это представляет реальную угрозу, если чипы используются на предприятиях военно-промышленного комплекса или в военной технике. 


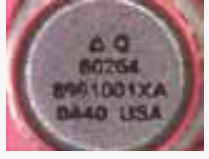

Вид сверху

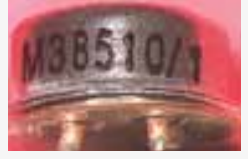

Вид сбоку
Рис. 1.

Пример

задвоенной

маркировки

\section{МЕТОДЫ ОБНАРУЖЕНИЯ ПОДДЕЛОК}

Основные методы обнаружения поддельных компонентов можно подразделить на физические и электрические. Физические методы включают в себя идентификацию, контроль маркировки, массогабаритных параметров, герметичности, рентгенологическое обследование, сканирующую акустическую микроскопию. К электрическим методам относят параметрический и функциональный контроль, а также электротермотренировку.

На этапе входного контроля важно проверять сопроводительную документацию, детально оценивать внешний вид и массогабаритные параметры, а также однородность партии. Тщательный входной контроль позволяет выявить следующие несоответствия по маркировке (рис. 1, 2):

- некорректная маркировка (например, неверный код даты, орфографические ошибки, просвечивающая старая маркировка);

- низкое качество маркировки;

- маркировка смывается растворителем.

Для контроля маркировки также используют методы акустической микроскопии, когда упругие механические колебания обеспечивают распространение волн в твердой среде.

Скрытые дефекты внутри компонентов позволяет выявить рентгенографическое оборудование (рис. 3). На этапе рентгенографического контроля можно определить наличие кристалла, постоянный размер / форму кристалла, целостность внутренних соединений, точное расположение кристалла и разводки.

Использование физических методов контроля в сочетании с электрическими повышает шансы выявления контрафактных изделий. Так, например, один из

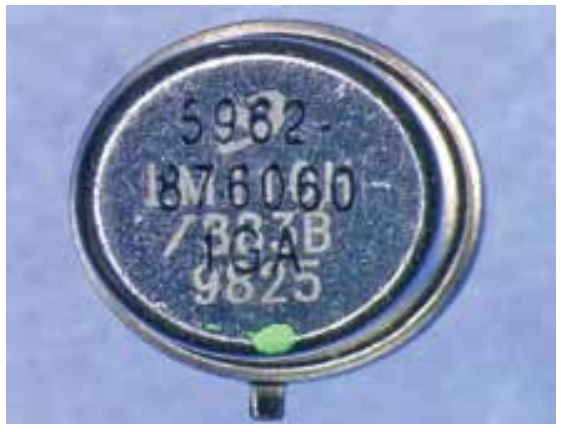

Рис. 2.

Пример перемаркировки

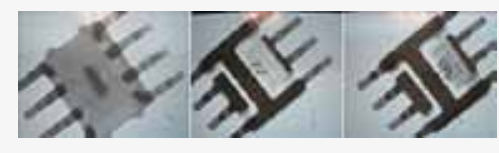

Рис. 3.

Рентгенографический контроль

способов определения однородности партии, помимо проверки дата-кодов, - контроль электрических параметров по ужесточенным нормам.

Комплексный набор испытаний должен включать в себя такие этапы, как контроль физических размеров, проверка постоянства всех маркировок, рентгеновские и электрические испытания. Электрические параметры должны проверяться на граничных температурах.

Важный этап отбраковки поддельных компонентов - электротермотренировка (ЭТТ). Метод ЭТТ основан на том, что для изделий электронной техники, в том числе микросхем, характерны отказы на ранней стадии работы (рис. 4) из-за наличия в поставляемой партии контрафактных изделий, скрытых дефектов, чем и обусловлены отказы с низкой энергией активации. ЭТТ помогает выявить внутренние и поверхностные дефекты элементов изделия, дефекты металлизации. Данный вид контроля позволяет отбраковать компоненты коммерческого уровня качества, замаркированные под военный уровень, а также отсеять уже находившиеся в длительной эксплуатации и повторно проданные как новые.

Для выявления несоответствий кристалла и внутренних соединений также используется разрушающий

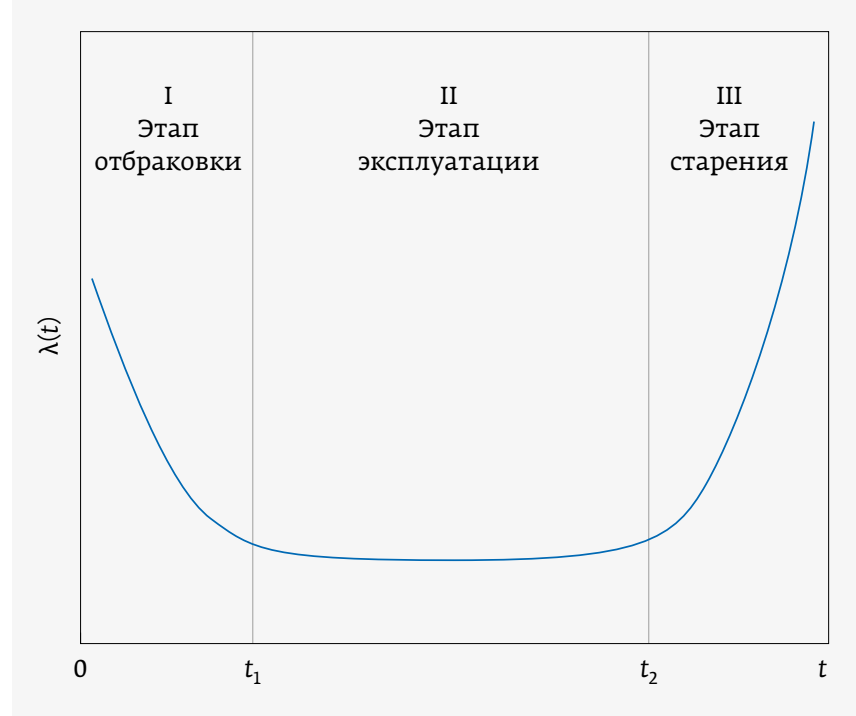

Рис. 4. Интенсивность отказов электронных компонентов в течение жизненного цикла изделия 
Рис. 5.

Вид микросхемы со вскрытым корпусом

физический анализ (РФА), который проводится на выборке изделий. В процессе РФА вскрывается (декапсулируется) корпус образца и оценивается внутреннее состояние компонента (рис. 5).

\section{ЗАКЛЮЧЕНИЕ}

Для снижения вероятности приобретения контрафактной продукции прежде всего нужно выбрать надежного поставщика. Необходимо приложить максимум усилий, чтобы обеспечить закупку изделий у основного изготовителя или официального дилера с полным набором сопроводительной документации. Каждая партия должна проходить 100\%-ный входной контроль, включая идентификацию, контроль внешнего вида, массогабаритных и электрических параметров.

Для выявления поддельных компонентов рекомендуется проводить комплекс испытаний, который может включать в себя такие этапы, как проверка физических размеров, постоянства всех маркировок, рентгеновские и электрические испытания.

\section{КНИГИ ИЗДАТЕЛЬСТВА ТЕХНОСФЕРА»}

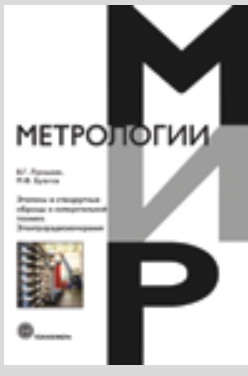

Цена 840 руб.

\section{ЭТАЛОНЫ И СТАНДАРТНЫЕ ОБРАЗЦЫ В ИЗМЕРИТЕЛЬНОЙ TEXНИКЕ. ЭЛЕКТРОРАДИОИЗМЕРЕНИЯ Лукашкин В. Г., Булатов М. Ф.}

Издание осуществлено при финансовой поддержке Федерапьного агентства по печати и массовым коммуникациям в рамках Федерапьной целевой программы "Купьтура России (2012-2018 20ды)"

В книге рассмотрены общие вопросы метрологического обеспечения и единицы физических величин. Изложены основные задачи технических средств метрологического обеспечения в области электрорадиоизмерений. Даны оценки погрешности и неопределенности первичных и рабочих эталонов.

Книга может быть полезна студентам и аспирантам при выборе и обосновании эталонной базы в области электрорадиоизмерений, а также специалистам, занимающимся вопросами разработки, производства и оценки качества средств измерений, контроля и испытаний. 


\section{ИСПЫТАНИЯ НА ВОЗАЕЙСТВИЕ ПАЕСНЕВЫХ ГРИБОВ}

\section{ИСПЫТАНИЯ ПРОВОАЯТСЯ В СООТВЕТСТВИЕ}

С ГОСТ 9.048, ГОСТ 20.57.416 И ГОСТ 20.57.306

ИспЫТАНИЯ проводятся с целью определения способности электронной компонентной базы, а таюже радиоэлектронной аппаратуры или их отдельных сборочных единиц и деталей противостоять росту грибов.

сУщность ИспытАния Заключается в том, что образцы, очищенные от внешних загрязнений, заражают водной суспензией спор грибов и выдерживают в условиях, оптимальных для их развития.

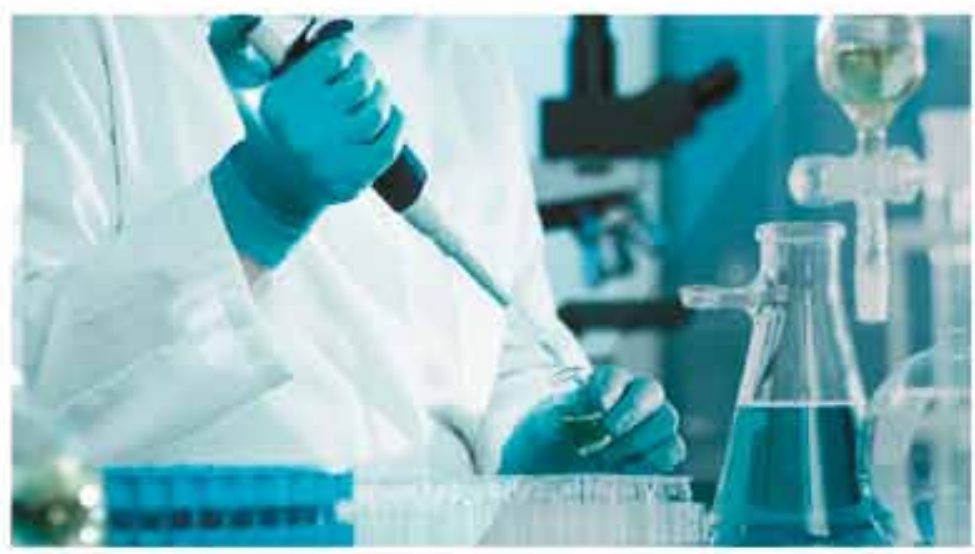

\section{ИСПЫТАНИЯ

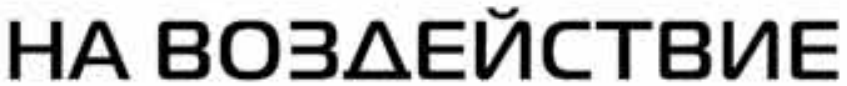 АКУСТИЧЕСКОГО ШУМА}

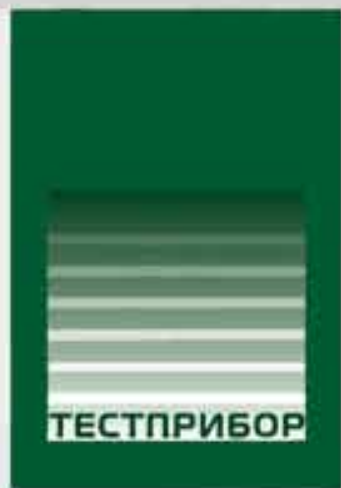

ИСПЫТАНИЯ ПРОВОАЯТСЯ В СООТВЕТСТВИЕ С ГОСТ 20.57.416 И ГOCТ 20.57.305

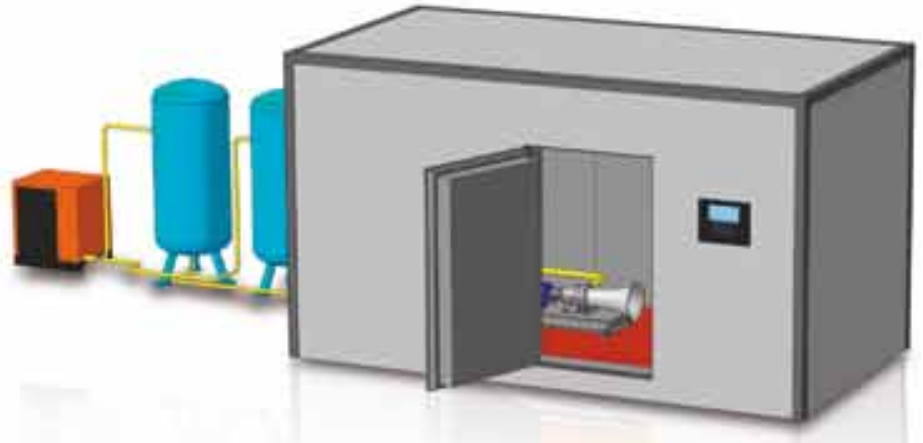

- Диапазон частот $50-10000$ Гц

- Максимальный уровень звукового давления - 160 дБ
испЫТАния проводятся с целью определения способности аппаратуры и электронной компонентной базы выполнять свои функции и сохранять свои параметры в пределах норм в условиях воздействия акустически наводимой вибрации.

Условия испытАниЙ аппаратуры характеризуются среднем уровнем звукового давления вокруг испытуемого обьекта, уровнем звукового давления в октавных полосах частот в одной из контрольных точек, разницей суммарных уровней в контрольных точках и длительностью испытаний. 